\title{
A face marcada: as múltiplas implicaçôes da vitimização feminina nas relações
}

\section{amorosas}

\section{| ' Suzana de Magalhães Dourado, ${ }^{2}$ Ceci Vilar Noronha |}

Resumo: $\mathrm{O}$ artigo analisa narrativas femininas sobre relações conjugais violentas, particularmente, casos nos quais ocorreram danos ao rosto da mulher agredida pelo parceiro. Foram objetivos da pesquisa: apreender os sentidos atribuídos pelas vítimas à violência vivenciada e identificar as implicaçōes decorrentes da experiência vitimizadora. $\mathrm{O}$ estudo foi realizado a partir de entrevistas com mulheres usuárias de instituições públicas nas áreas da segurança pública, saúde, assistência psicossocial e educação. Elaborada sob a ótica da sociologia do corpo que reconhece a face como locus privilegiado, a análise evidenciou o caráter invasivo das agressões ao rosto feminino ao produzirem marcas físicas e emocionais que vão repercutir, a curto e longo prazo, na vida das mulheres. À luz da perspectiva feminista relacional, emergiram questóes atinentes a ambos os cônjuges na produção do convívio violento, mediadas pelas construçōes sociais de gênero. Reverberaçōes das agressōes sobre o sentimento de identidade e da depreciação da autoimagem foram enfatizadas como geradoras de intenso sofrimento psíquico. Além disso, os resultados apontaram para limites no modelo de atenção biomédico, ainda predominante nos serviços de saúde, para lidar com a complexidade envolvida na vitimização conjugal feminina, bem como para a necessidade de articulação das várias áreas de atuação que tangenciam esse fenômeno.
1 Serviço Médico-Odontológico Instituto Federal de Educação, Ciência e Tecnologia da Bahia. Salvador-BA, Brasil. Endereço eletrônico: suzana.m.dourado@ gmail.com

${ }^{2}$ Instituto de Saúde Coletiva, Universidade Federal da Bahia. Salvador-BA, Brasil. Endereço eletrônico: ceciavilar@gmail. com 
$\mathrm{O}$ artigo aborda experiências de vitimização feminina em relações conjugais violentas, estudando casos em que a violência física acarretou danos ao rosto da mulher agredida. Constituiu-se objetivo do trabalho desvelar os significados atribuídos pelas mulheres à violência vivida, bem como analisar as implicaçôes da experiência vitimizadora à vida e à saúde das participantes, tanto as que concernem aos aspectos subjetivos, quanto outras, que envolvem o entorno de suas relações sociais. Neste sentido, a análise, fundamentada teoricamente nas Ciências Sociais, aborda as consequências dos eventos violentos às subjetividades envolvidas numa situação de trauma facial, decorrente das agressões intencionais entre parceiros íntimos.

A violência de gênero contra a mulher tem sido reconhecida como problema de saúde pública, violação dos direitos humanos e, em muitos países, a exemplo do Brasil, como crime. Quanto ao locus de ocorrência, há uma convergência dos estudos nesta temática em apontar o domicílio como o ambiente onde mais acontecem as agressóes e, como autor mais frequente, alguém que mantém ou manteve um relacionamento afetivo com a vítima, seja como marido, companheiro ou namorado (GARCIA-MORENO et al., 2006; HEISE; GARCIA-MORENO, 2002). Conquanto mulheres possam se constituir em ofensoras e a violência também ocorra em relações homoafetivas, este trabalho focaliza casos nos quais homens atuaram como agressores de suas parceiras.

Outro consenso de muitas produções tem sido o de evidenciar os efeitos deletérios da violência à saúde das mulheres vitimizadas, seja esta violência física ou psicológica. Nos casos de violência física, a maior parte dos estudos se reporta à cabeça, notadamente, ao rosto feminino como parte do corpo mais atingida (SADDKI; SUHAIMI; DAUD, 2011; SCHRAIBER et al., 2002; LE et al., 2001). Embora esta preponderância esteja, epidemiologicamente, bem documentada em pesquisas nacionais e internacionais, na revisão bibliográfica que efetuamos, ainda no período pré-campo, não conseguimos identificar nenhum trabalho que buscasse depreender os sentidos atribuídos pelas mulheres às agressões que lhes atingiram a face. Dado o alto valor simbólico do rosto para a identidade pessoal e para a autoestima, sobretudo nas sociedades modernas que têm na aparência física e na estética corporal (feminina, primacialmente) alguns 
dos seus mais cultivados valores, debruçamo-nos sobre o tema em foco, a fim de descortinar a dimensão subjetiva de tal vitimização.

\section{Estratégias metodológicas}

O estudo foi desenvolvido com metodologia qualitativa, em caráter retrospectivo, empregando a entrevista narrativa como técnica de coleta de dados. ${ }^{1}$ Os sujeitos de pesquisa somaram 14 mulheres com história de dano facial decorrente de violência conjugal. $\mathrm{O}$ grupo formado apresentou heterogeneidade quanto ao nível socioeconômico, escolaridade, idade (27 anos a mais jovem e 52 anos a mais idosa), cor da pele e estado civil de cada participante. À época das entrevistas, cinco das informantes permaneciam com os parceiros e as demais haviam se separado. $\mathrm{O}$ acesso a estes sujeitos se fez através da intermediação do serviço de assistência social de quatro órgãos públicos, sediados em Salvador, pertencentes a quatro searas de atuação: esfera policial, assistência psicossocial, setor de saúde e uma instituição de ensino. Tais escolhas favoreceram a construção de um cenário de pesquisa abrangente e rico, uma vez que a violência entre parceiros íntimos costuma envolver múltiplos campos institucionais de atuação.

As entrevistas se deram, após consentimento por escrito das participantes, entre julho e novembro de 2012, em salas reservadas das instituições participantes, visando salvaguardar o bem-estar das integrantes da pesquisa, garantindo-lhes anonimato e segurança. Foram disponibilizados, igualmente, encaminhamento psicossocial e odontológico conforme as necessidades apresentadas durante os encontros, acesso ao conteúdo de tudo o que foi compartilhado nas entrevistas, e ainda assegurada, a cada uma, a liberdade de recusar-se a ceder qualquer informação, se assim fosse sua vontade.

Como método analítico, elegemos a análise de conteúdo temática, a nosso ver, mais adequada aos objetivos propostos (BAUER, 2002). As falas das informantes foram reorganizadas por categorias de significados, sob a ótica da sociologia do corpo como entendida por Le Breton (2009; 2006), procurando estabelecer nexos entre os discursos e a perspectiva feminista relacional, a qual entende que ambos os cônjuges participam da construção de um convívio violento, ainda que de forma diferenciada e mediada por valores sociais de gênero (GROSSI, 1998; MACHADO; MAGALHÃES, 1998). 


\section{Vitimização}

Houve grande diversidade no tipo de convívio violento experienciado pelas mulheres participantes da pesquisa. Os relatos variaram desde uma pungente narrativa acerca de agressôes físicas e psicológicas praticadas pelo cônjuge agressor ao longo de 13 anos, até outro caso em que houve um único episódio de violência física em 12 anos de relacionamento. Ainda assim, no conjunto das falas, predominaram situaçóes de sofrimento, tanto físico quanto emocional, e, potencialmente, capazes de provocar repercussóes nefastas de longo prazo em suas vidas. Por entendermos que a violência conjugal ocorre dentro de uma relação afetivo-sexual e, por isso mesmo, numa via de mão dupla, reconhecemos que as consequências deste tipo de interação vão recair sobre ambos os atores envolvidos, ainda que de forma diferenciada (PAZO; AGUIAR, 2012; SARTI, 2005; GROSSI, 1998; MACHADO; MAGALHÃES, 1998).

Ao falarmos em vitimização e ensejando situar nossa abordagem em meio a tantas outras sobre o tema, julgamos apropriado dirigirmos brevemente o olhar para o papel da mulher nos conflitos conjugais. Alguns trabalhos sugerem uma visão da mulher como ser passivo, indefeso e vitimado por um macho opressor que, por sua vez, é legitimado por uma ideologia dominante na sociedade (FEIGUIN; BORDINI, 1987; AZEVEDO, 1985). Nossa reflexão caminha no sentido de enxergar para além do binômio algoz-vítima, e perceber a mulher como protagonista-vítima, por não considerarmos os termos excludentes entre si. Protagonista, porque como parte constituinte da relação, a mulher também atua na tessitura afetiva, participando da sua construção, mas igualmente vítima, na medida em que a interação se dá num cenário historicamente forjado, onde a ideologia machista ainda permeia as relações e são as mulheres que, majoritariamente, sofrem abusos físicos e psicológicos em relacionamentos violentos (PAZO; AGUIAR, 2012; SAFFIOTI, 2004; GROSSI, 1998).

Quanto à vitimização, este tem sido um conceito largamente usado pelo direito criminal que a relaciona ao dano derivado de um ato delituoso. Domínguez (2010), fazendo uma abordagem mais ampla do conceito, considera vitimização um processo pelo qual o sujeito passa ao enfrentar um evento traumático (seja da ordem do crime ou não) e suas consequências. Baseado num entendimento mais recente da vitimologia, este autor afirma que "el estudio de la vitimización, en tanto que fenómeno complejo, obliga a considerar los factores (individuales, 
sociales, culturales) que condicionan o modulan el modo de vivir la experiencia referida" (DOMÍNGUEZ, 2010, p. 3). Ou seja, o mesmo tipo de acontecimento traumático será vivido de forma diferente por pessoas inseridas em contextos distintos, ainda que com possíveis similitudes em muitos aspectos.

No mesmo sentido dessa afirmação de Domínguez (2010), as entrevistas revelaram experiências de vitimização feminina singulares e diversas. No entanto, os muitos pontos em comum que recortaram todas elas permitiram, no processo de análise, a identificação dos núcleos de sentido que serão abordados neste artigo, quais sejam: invasão do corpo; agressões intencionais ao rosto; significados atribuídos às marcas faciais; importância do olhar alheio; violação do atributo da beleza e, ainda, ameaça à identidade pessoal.

\section{Corpo: um território invadido}

Agressōes físicas num relacionamento amoroso tendem a gerar forte carga subjetiva para os envolvidos que vai além das lesões resultantes. No entanto, é pertinente não considerar os efeitos subjetivos mais relevantes do que aqueles produzidos no corpo vitimizado. Aquilo que afeta o espaço corporal atinge também a subjetividade e vice-versa. A concretude do corpo não pode ser desvinculada do âmbito subjetivo, nem uma esfera ser subordinada a outra. São instâncias imbricadas e indissociáveis da vida humana.

Uma das entrevistadas emitiu sua percepção acerca da agressão facial que sofreu numa desavença com o marido com as seguintes expressões:

[...] eu acho assim, o rosto é a foto que a gente mostra, é a carteira de identidade, é a nossa... a nossa marca, né? Eu acho isso. Eu acho que é pra agredir a minha marca, a minha pessoa. (Lara, 44 anos). ${ }^{2}$

Esta fala suscita uma reflexão sobre a acepção de "marca" no contexto da violência em foco. $\mathrm{O}$ verbete, polissêmico na língua portuguesa, traz em sua raiz latina a noção de limite, fronteira. Este é o significado que pretendemos abordar e ao que parece se referir a entrevistada. É dele que provém "demarcação", estabelecimento de limites através de marcos. Nesse sentido, Le Breton usa a terminologia "marca" ao se referir ao corpo: "[...] o corpo quando encarna o homem é a marca do indivíduo, a fronteira, o limite que o distingue dos outros" (LE BRETON, 2006, p. 10). Assim, o corpo pode ser visto como o território primeiro do sujeito, a partir do qual ele constrói suas relaçôes com o mundo. E 
dentro do leque de relaçôes que os indivíduos estabelecem estão as interações afetivo-conjugais, incluindo aquelas onde há violência. Então, sendo o corpo um território, infligir um golpe de violência física no cônjuge (no caso de Lara, na face) representaria uma ultrapassagem arbitrária de limites, uma invasão do espaço corporal.

Ainda pensando o corpo vitimizado como território relacional invadido, é pertinente citar mais uma das falas coletadas em campo:

[...] porque isso aqui é o meu espaço (apontando com as duas mãos para o próprio corpo), a pessoa chegar aqui em mim pra me agredir? Não tem porque. Eu escuto muito bem, a pessoa pode falar comigo que eu tô ouvindo. Agora, chegar e me pegar pelo pescoço e me apertar ou fazer inúmeras coisas que se fazem por aí? (Catarine, 31 anos)

Ao chamar o corpo de "meu espaço", Catarine estabelece um limite de acesso a esse território (não respeitado pelo companheiro), apontando outra forma de comunicação possível, que não a violenta. Machado e Magalhães (1998) relataram as dificuldades de alguns parceiros em lidar de maneira pacífica com os conflitos que emergem na esfera doméstica, recorrendo à violência física como um recurso mais "eficaz" do que outras formas de negociação que exigiriam maior investimento afetivo. Ademais, o cenário social onde a violência conjugal eclode é também caracterizado pela vigência da ideologia machista entremeando as relações de gênero, tendo como resultante a naturalização da dominação masculina. Em tal contexto, é possível supor que, o que Catarine chama de "o meu espaço”, não seja percebido dessa forma por seu par afetivo. Assim, o que para ela constitui um território invadido, para ele signifique um território dele e por ele próprio demarcado.

Em relação à demarcação, como já citado no início desta seção, esta se refere ao uso de marcos ou marcas para a delimitação do espaço visado. Aqui está mais um sentido para "marca": um sinal, um selo, um timbre, apontando para quem o produziu. É a isso que se referem Femenías e Rossi quando versam sobre o corpo feminino sendo historicamente concebido como lugar de demonstração do poder masculino, bem como um território a ser demarcado para sinalização pública desta sujeição:

Los cuerpos de las mujeres siempre han tenido un valor simbólico adicional como garantía de sutura de conflictos o como lugar de ejercicio de poder para humillar, deshonrar, negar o enviar mensajes cifradas a otros varones (FEMENÍAS; ROSSI, 2009, p. 53). 
Em relação à marca facial provocada pela agressão do companheiro, uma das participantes alude ao aspecto simbólico agregado ao sinal corporal naquele sítio em particular:

[...] no rosto fica na cara, você olha no espelho e fica traumatizada, seu rosto não é mais o mesmo, ficam hematomas, entendeu? E é diferente do que em seu corpo. Quantas vezes você toma uma pancada e tal, aí você pode até pensar assim: "Não. Foi uma pancada (não causada pelo parceiro)". Mas no seu rosto, não. Você lembra que ele te agrediu, é uma marca que fica. (Beatriz, 28 anos).

Interessante notar que neste trecho ela não se refere à mensagem deixada para outros verem e sim ao próprio olhar sobre seu corpo invadido e marcado. A mensagem chega primeiro a ela. A imagem que o espelho reflete, mostra mais do que um sinal, remete ao sofrimento vivido. A marca deixada parece funcionar como uma bandeira fincada a indicar que, de alguma forma, ele (o parceiro que a agrediu) também está ali. Entendemos ser essa uma demarcação perversa do território corporal e uma das facetas mais dolorosas da violência entre parceiros íntimos (MACHADO; MAGALHÃES, 1998; AZEVEDO, 1985).

\section{$\mathrm{O}$ rosto como alvo}

Partindo do pressuposto que, em muitas culturas, o rosto é uma das partes mais valorizadas do corpo, sobretudo quando se trata do corpo feminino, bem como pelo que já foi analisado até o momento, é possível inferir que o dano associado a essa região e o sofrimento dele resultante, quer sejam de natureza moral, física, temporária ou permanente, possuam forte carga simbólica tanto para quem sofre o dano quanto para quem o provoca.

De acordo com algumas pesquisas na área da traumatologia buco-maxilofacial, a alta prevalência de lesões faciais traumáticas em homens e mulheres atendidos em serviços de saúde se deve, principalmente, à grande exposição e pouca proteção oferecida à região da cabeça e, mais especificamente, ao rosto (CARVALHO et al., 2010; MACEDO et al., 2008). No entanto, a nosso ver, essa atribuição objetiva, baseada em causa e efeito sobre a estrutura corpórea, precisa ser vista com cuidado ou precisa ser relativizada, levando em consideração as situações que originaram as lesões. No contexto da violência interpessoal entram em jogo aspectos mais subjetivos do que aqueles a serem observados em ocorrências de acidentes domésticos e de trânsito, por exemplo. 
Quando focalizamos estudos sobre violência conjugal, embora haja grande diversidade teórica e metodológica, há certos pontos onde a convergência é bastante significativa. Entre eles, além da já conhecida predominância de parceiros e ex-parceiros íntimos como principais agressores, dados epidemiológicos também apresentam consonância ao apontar, nos casos de violência física contra a mulher, a região da cabeça e pescoço e, particularmente, a face como principal alvo das agressões.

Duas das entrevistadas enfatizaram que, em todos os episódios de violência por elas vivenciados, os parceiros sempre intentavam atingir a região facial, ou seja, havia uma decisão em direcionar os golpes. Os excertos abaixo, resultantes do diálogo com Mônica (47 anos), são bem eloquentes sobre a intencionalidade do parceiro:

Pesquisadora: E alguma vez ele lhe atingiu no rosto?

- Sempre tapa na cara, sempre.

[...] por uma discordância, ele veio pra cima de mim, e aí já veio no rosto. [...] eu fiquei acuada no sofá e ele sempre no rosto, muuuuito, só no rosto.[...] os tapas eram sempre faciais, sempre na cara, sempre, sempre muito na cara [...] de pescoço prá cima. Não chutava, pouco me apertava, pouco me empurrava, mas puxar cabelo, bater na cara [...].

Lara (44 anos), também enfatizou a intencionalidade do companheiro em atingir sua face:

[...] da primeira vez eu não dei queixa, ele me deu um murro no rosto. (Depois) ele tornou a me dar um murro no rosto na frente dos meninos [...] o negócio dele era dar murro no rosto.

Pelo conteúdo dos recortes, pode ser observada a percepção, por parte das mulheres, da intencionalidade dos companheiros em feri-las no rosto. Com as expressões "sempre tapa na cara" e "só no rosto", Mônica caracteriza uma mobilização constante da vontade do marido em atingi-la nesse local em particular. Ou seja, o rosto não era atingido por estar mais exposto ou sem proteção, era "alvejado" propositalmente. Quando perguntada ao que atribuía a conduta do marido de sempre visar o seu rosto nos episódios de violência física, ela respondeu:

O calar a boca. É a boca, é a língua. Se ele pudesse arrancar... se ele tivesse o poder [...] eu seria de língua cortada. É calar, é calar. (Mônica, 47 anos). 
No entender da entrevistada, o marido age usando a linguagem da violência física como um meio de suprimir sua fala. Aliando esse a outros momentos de sua narrativa, depreende-se que, em algum momento do convívio, os canais de comunicação começaram a ser subvertidos e o conflito, comum em qualquer interação humana, passou a adquirir contornos violentos até chegar às agressões corporais.

Chama-nos a atenção o caráter relacional da violência demonstrado na forma como os poderes circulam nessa interação diádica. Quando o marido manifesta um poder através da força física contra a esposa, esta força parece estar sendo empregada de forma a anular outro poder, aquele exercido por ela através da fala. Por isso a boca é o alvo, já que é dali que o desafio provém. O conflito interpessoal se revela como um processo de colisão entre poderes e subjetividades que se opõem (SUÁREZ; BANDEIRA, 2002). É um movimento relacional, ainda que se dê de forma desequilibrada em termos do uso da força física.

\section{A face marcada}

As agressões à face podem ser, segundo Halpern (2010), uma das formas encontradas pelo parceiro agressor de reforçar o domínio e o controle sobre a mulher. Esse autor sugere que as marcas deixadas atuariam como lembranças do poder exercido, através dos efeitos posteriores à violência praticada. Assim, cicatrizes, perdas dentárias, disfunçōes mastigatórias, bem como sequelas emocionais persistiriam como marcas ou lembretes dolorosos do abuso.

Retornamos ao depoimento já mencionado de Beatriz (28 anos), que exemplifica o entendimento acima exposto:

[...] no rosto fica na cara, você olha no espelho e fica traumatizada, seu rosto não é mais o mesmo, ficam hematomas, entendeu? [...] Você lembra que ele te agrediu, é uma marca que fica.

É importante perceber que ela não se refere a uma marca física permanente, já que o hematoma é uma lesão temporária, mas ainda assim, refere-se a "uma marca que fica". Assim, o termo "traumatizada" é usado aqui para definir uma dor psíquica, um trauma emocional. Ou seja, para ela, o que permanece é a lembrança da agressão cometida pelo parceiro (com quem mantém um vínculo amoroso) e por isso ela sofre. Esse tipo de marca corporal é passageira, desaparece. Todavia, a marca do sofrimento não é superada no mesmo compasso. 
Ao discorrermos sobre marcas psicológicas, não pretendemos minimizar o significado de cicatrizes e lesões permanentes, às quais nos reportaremos a seguir. O intuito é trazer à luz concepçôes de "marca" coerentes com as vivências analisadas no presente estudo. Nesse sentido, encontramos na literatura consultada algumas referências à maior facilidade que as mulheres teriam de superar determinados tipos de violência física em relação à violência psicológica. Por outro lado, foinos perceptível que a abordagem biomédica privilegia os efeitos da primeira em detrimento da segunda. Estas posições, aparentemente opostas, nos fazem refletir que a tentativa de comparar o dano causado por uma ou por outra pode levar ao dualismo soma/psique que, apartando esferas imbricadas, dificulta uma compreensão mais aproximada do fenômeno.

Sendo assim, ao falarmos das marcas visíveis produzidas no rosto feminino em decorrência da violência conjugal, entendemos que estas marcas físicas não ocorreram isoladamente. Elas se deram num contexto impregnado de emoções contraditórias e num ambiente doméstico conflituoso, com implicaçôes psicológicas na vida dos envolvidos. Além disso, classificar as diversas modalidades de violências pode se mostrar útil como ferramenta didática e jurídica, no entanto, quando se pretende compreender suas dinâmicas, nos parece apropriado abordálas em associação.

Partindo desse pressuposto, é válido pensar que, numa cultura na qual o rosto detém elevado valor simbólico e cuja importância é diferenciada em relação às demais regiōes do corpo, uma alteração ocorrida em qualquer outro sítio corporal provavelmente será menos perturbadora do que aquela exposta na face. Parece ser a isso que Le Breton se refere ao dizer:

O valor ao mesmo tempo social e individual que distingue o rosto do resto do corpo, sua eminência na apreensão da identidade é sustentada pelo sentimento que o ser inteiro aí se encontra. A infinitésima diferença no rosto é, para o individuo, o objeto de uma incansável interrogação [...] (LE BRETON, 2006, p. 71).

Ou seja, a primazia dessa parte do corpo faz com que sua violação se revista de sentidos que vão além da esfera anatômica. Alguns depoimentos obtidos durante as entrevistas refletem essa concepção:

[...] pra mim foi horrível quando eu olhei a marca no meu rosto [...] não queria que fosse em outra parte do corpo, mas pra mim se fosse, seria até mais razoável. (Fátima, 33 anos). 
Logo no rosto, né? Logo no rosto. Até hoje eu escuto certos tipo de coisas [...] é dife-

rente porque fica marcado. [...] Eu tento esquecer, eu esqueço. Tento, não, eu tenho que esquecer. Agora isso aqui (apontando para as cicatrizes no rosto) nunca esquece, né? Nunca, nunca esquece. (Elisabete, 28 anos).

Cada uma das falas confirma, à sua maneira, a singularidade do rosto descrita pelo autor referenciado, sendo que Fátima acrescenta a descrição de seu sentimento ao se olhar no espelho após a agressão: o horror irrompeu ao identificar em si mesma um sinal incontestável da dor vivida exposto num local, a seu ver, privilegiado em relação aos demais.

Já o último trecho traz a percepção de Elisabete, que precisou passar por uma intervenção cirúrgica na face, cerca de quatro anos antes da entrevista, em razão de fratura mandibular dupla, provocada por um murro desferido pelo ex-companheiro que não aceitava o fim do relacionamento proposto por ela. Podemos inferir, através de seu enunciado, que violência física e emocional se imiscuem, conformando um sofrimento conjunto. A dor proveniente da fratura cessou enquanto lesão corpórea, mas, de certa maneira, continua inscrita no rosto de Elisabete, uma vez que, ao se deparar com as marcas deixadas, ela padece.

Dessa forma, as marcas configuram uma revitimização de longo prazo na vida da mulher agredida, difícil de ser superada sem ajuda apropriada. Estes relatos nos remetem à percepção citada no início desta seção sobre o papel da face marcada como um "lembrete" cruel do poder e do domínio masculinos exercidos através da violência.

\section{O olhar dos outros}

Após nos referirmos a alguns dos desdobramentos da violência praticada contra a mulher no âmbito conjugal no que concerne às marcas deixadas quando a face é ferida pelo parceiro amoroso, pretendemos mover o foco para possíveis repercussōes do olhar alheio na significação dessas marcas.

À exceção de alguns grupos sociais que, por motivos religiosos, climáticos, ou desejo voluntário de ocultação da identidade, entre outras razões, encobrem parcial ou totalmente a cabeça e a face, para a maioria dos povos ocidentais estas são as partes do corpo que oferecem maior visibilidade. E justamente por estar mais à vista, o rosto está também mais sujeito à apreciação e ao julgamento de outros atores que fazem parte do mesmo cenário social. Este "olhar dos outros" 
assume papel primordial nas interações humanas e vai influenciar sobremaneira os sentidos atribuídos às agressões ao rosto feminino.

A face humana parece funcionar como uma espécie de vitrine ao expor aos outros não só os elementos físicos do rosto, mas também ao exteriorizar aspectos da subjetividade por intermédio de expressões faciais que transmitem sentimentos e emoções (LE BRETON, 2009; YU, 2001). Além disso, é principalmente através do rosto que a comunicação entre pessoas se processa, por meio do olhar, da fala e da escuta. Há aí um movimento reflexivo, assim como nas vitrines: a exposição de um lado e a avaliação, de outro. Isso não quer dizer que aquilo que é mostrado corresponda efetivamente ao que é visto, já que se trata de seres humanos complexos, com fatores individuais e coletivos engendrando tanto intenções, quanto percepções.

Muitas entrevistadas revelaram uma preocupação acentuada com o olhar dos outros sobre as marcas aparentes da violência conjugal vivida.

[...] ele uma vez deu um murro no meu rosto que partiu. Eu tive que ir pro HGE e levei ponto no rosto [...] se ele me batesse em outro lugar, eu poderia esconder e no rosto eu não tenho como esconder. (Alice, 27 anos)

O rosto desse tamanhão assim (mostrando com as mãos). Todo mundo (perguntava): "O que é isso? O que é isso?" - "Eu caî". Uma outra pessoa perguntava e eu com vergonha, muita vergonha de dizer. (Ilka, 43 anos)

Le Breton, ao falar das emoções que podem brotar no indivíduo quando se percebe como alvo de observação, sustenta que "em nossas sociedades ocidentais, os sentimentos como a vergonha, culpabilidade ou embaraço subentendem o julgamento alheio, real ou potencial” (LE BRETON, 2009, p. 94). Quer dizer, sentimentos de vergonha, culpa ou embaraço, muitas vezes são experienciados independentemente da manifestação dessa avaliação crítica por parte dos outros.

A frase "contemplar o outro é como tocá-lo de maneira simbólica" (LE BRETON, 2009, p. 12) é uma bela afirmação, prenhe de significados. Nela o autor alude à tatilidade do olhar humano e à multiplicidade de afetos entranhados nesse gesto. Justamente por causa destas características, o olhar pode ser interpretado de diferentes formas por parte daquele que se torna seu objeto. Um dos depoimentos colhidos no trabalho de campo apresenta uma percepção sobre o olhar do outro como algo muito relevante para análise:

As pessoas sempre perguntam “o que foi isso? Foi acidente?". E às vezes é um constrangimento de você chegar e dizer que foi uma agressão de seu ex-companheiro, 
pelo fato até deles às vezes pensar: “será que ela num fez nada de errado?", e você não

fez. E você fica se sentindo humilhada e constrangida, porque muitos pensam assim, não que ela faz, mas eu já vi muitos dizer "ah, às vezes ela traiu” e não é por aí, nem sempre. Às vezes pode até ocorrer uma traição, mas no caso de muitas não é isso. E aí a gente fica bastante constrangida. (Gisele, 29 anos).

Ao ser questionada, por terceiros, sobre a origem das cicatrizes no seu rosto, Gisele se sente tocada de maneira incômoda pelas perguntas (e pelo olhar que as gerou), pois aquelas indagações lhe acionam a memória do ocorrido. E ainda mais, despertam nela o receio de que lhe atribuam a "culpa" por carregar aquelas marcas. Observa-se aqui o drama da revitimização vivido por essa participante ao ter que, frequentemente rememorar, por causa de uma bandeira sinalizadora inserida pela força no território do seu corpo, a violência que sofreu do ex-companheiro. Chama-nos atenção, ainda, o sentimento de humilhação e constrangimento que nela aflora ao imaginar que aqueles olhares também simbolizam um julgamento moral de sua conduta. No seu entendimento, se ela tivesse traído o parceiro, talvez a violência fosse justificável. Mas ela insiste em reforçar: "não é por aî". Parece haver uma embaraçosa sensação de não saber o que os outros "realmente" estão pensando a seu respeito. O fato de, a seu ver, "não ter feito nada de errado", potencializa seu sofrimento e sua perplexidade ante a experiência traumática que viveu e que ainda revive a cada olhar inquiridor sobre suas marcas.

\section{Beleza violada}

Alguns autores trazem, como uma das suposiçôes explicativas para a alta prevalência de lesões no rosto de vítimas de parceiro conjugal, a intenção do agressor de afetar o atributo da beleza facial, culturalmente investido de alto valor simbólico nas sociedades hodiernas, especialmente para as mulheres (SARDENBERG, 2002; AZEVEDO, 1985). Além de outros fatores imbricados na gênese da violência entre cônjuges, não podemos deixar de pensar no papel desempenhado pelo valor cultural da beleza no cenário das relaçôes conflituosas entre parceiros íntimos.

É numa sociedade que cultua o belo, que dita quem e o que é bonito ou feio, que homens e mulheres têm se desdobrado para corresponder aos apelos midiáticos de beleza. Sardenberg se refere à utilização das técnicas de embelezamento, assinalando diferenciais de gênero que fazem recair sobre a mulher um maior envolvimento nesse processo de busca da beleza "ideal": 
[...] as tecnologias do corpo se aplicam tanto a homens quanto a mulheres [...] mas é certo que a construção da mulher como objeto de desejo, como é próprio das sociedades contemporâneas ditas ocidentais, resulta em investimentos maiores por parte das mulheres em seguir os padróes estéticos impostos ao seu sexo (SARDENBERG, 2002, p. 60).

O papel atribuído de objeto de desejo implica um poder de sedução sobre o "desejante", então, com vistas a exercer esse poder no jogo amoroso, a grande maioria das mulheres se empenha na valorização de características físicas pessoais também através dos cuidados faciais: uso de maquiagem, remoção de pelos e manchas, delineamento de sobrancelhas etc. É como se diz no cotidiano: "produzir-se toda" para ficar bonita. Assim, o sentir-se bela e, portanto, desejável, faria parte da busca feminina por reconhecimento e apreço por parte do seu par romântico. A beleza seria um dos meios usados para conquistar o afeto do outro. Se essa "arma" lhe é subtraída, instala-se uma lacuna na percepção da autoimagem daquela que teve sua beleza violada de forma violenta por alguém que, segundo as normas sociais prescrevem, ela deveria seduzir. Para além disso, a face maculada pode também representar uma possível defasagem na capacidade presumida de construir novos relacionamentos amorosos.

Machado e Magalhães percebem, num quadro dramático de violência entre cônjuges que resultou na mutilação dentária parcial da mulher agredida, a conexão com a intencionalidade referida no início desta seção:

A marca de sua (da mulher) degradação é visível a todos, foi inscrita no corpo. O marido lhe arrancou os dentes, retirou sua beleza. Arrancou dela, junto com os dentes, qualquer poder de sedução que pudesse ter. Arrancar seus dentes foi um "argumento" a mais que seu marido conseguiu para lhe tirar a liberdade (MACHADO; MAGALHĀES, 1998, p. 14).

Este recorte aponta para a subjetividade contida na violência física a que nos referimos anteriormente. $\mathrm{O}$ ato foi físico, de força, mas o propósito era atingir também algo precioso da ordem do simbólico: o poder de sedução e a liberdade feminina.

De forma marcante, algumas participantes do grupo estudado expressaram sua tristeza e inconformismo em ter que conviver com as sequelas aparentes das agressões faciais que comprometeram sua beleza, uma delas foi Ilka (43 anos):

Me produzi toda, fiquei toda bonita, eu disse: "hoje eu vou ficar bonita lá pra todo mundo, a primeira vez que eu vou num lugar, eu num vou chegar lá parecendo um negócio feio”. Aí fui, fiquei bonita, foi o meu fim. [...] Aí ele me jogou lá no chão, foi 
que eu quebrei isso aqui (apontando a face) a boca aqui, o nariz, o meu rosto. Fiquei

toda deformada, fiquei feia, feia, mas sabe o que é feia? E você olhar no espelho, ver o antes e o depois? É muito revoltante. [...] E hoje eu me sinto assim olhando pra meu rosto, eu era uma mulher muito bonita, hoje eu tenho vergonha de olhar pra mim porque um homem marcou o meu rosto. E eu não vou aceitar isso nunca.

A narrativa de Gisele (29 anos) também denota o efeito deletério das lesões faciais à autoimagem da mulher vitimizada frente à sua concepção da beleza como recurso de sedução:

Ele (o homem) só... às vez só dá valor quando a mulher tá muito bonita, bem arrumada. Se a mulher passa por alguma dificuldade, ele já vai olhando pra outra.

[...] eu lembro de que eu fui morar com ele, eu tinha a pele bonita, o corpo bonito, depois fiquei com o corpo todo deformado, todo marcado, tudo isso.

Nos dois casos parece haver clara demarcação entre a aparência anterior ("muito bonita"; "pele bonita, corpo bonito") e a posterior ("toda deformada"; "corpo todo deformado") à violência vivida. No entender delas, o corpo (não só o rosto) ficou todo deformado. É dessa forma que elas se percebem. Como diz Le Breton: "O valor ao mesmo tempo social e individual que distingue o rosto do resto do corpo, sua eminência na apreensão da identidade é sustentada pelo sentimento que o ser inteiro aí se encontra" (LE BRETON, 2006, p. 71). Num contexto onde o padrão hegemônico de beleza feminina prescreve que o menor sinal do processo natural de envelhecimento na face deve ser apagado através das inúmeras técnicas disponíveis (SARDENBERG, 2002), uma cicatriz no rosto pode significar a perda do "direito" a ser considerada, inclusive por si e para si mesma, bonita outra vez.

\section{Ameaças à identidade}

Entendendo que identidade é a percepção que o indivíduo tem de si em relação ao mundo e, ao mesmo tempo, um produto da interação entre ele próprio e o universo sociocultural à sua volta, podemos inferir que a identidade não é algo dado biologicamente, mas que é definido num processo histórico. Ou seja, dependendo do momento de vida e das circunstâncias vivenciadas, a concepção de identidade se reorganiza (ou desorganiza) num movimento de formulação contínua (ZANATTA, 2011).

Dessa forma, a identidade está sempre sendo tecida, moldada, desenvolvida num movimento dialético entre o individual e o social. Esse intercâmbio entre as percepções objetivas e subjetivas a respeito de si e as percepções objetivas e 
subjetivas dos outros sobre si, inerente às trocas sociais, vai conferir vulnerabilidade ao sujeito que se encontra em um ambiente de conflito crônico, como é o caso de muitas relações conjugais violentas.

No grupo pesquisado, houve muitos relatos de situações em que, além da violência física sofrida, as informantes também se sentiram alvos da violência psicológica por parte dos companheiros, em alguns casos por longo período de tempo. Uma das entrevistadas narrou experiências em que as palavras insultuosas do marido visavam lhe desqualificar, pondo em dúvida suas capacidades e competências, ameaçando assim sua identidade pessoal e minando também a autoestima já, de alguma forma, fragilizada pela deterioração dos canais de comunicação do relacionamento. Em suas palavras:

[...] começou com xingamentos, né, começou: "você é burra", "você...você não faz nada direito" [...], "sua idiota, sua burra, sua isso, sua aquilo, meu filho vai cagar na sua boca", desmerecimento total.

[...] me ameaçou que sem ele eu não taria com nada, não ficaria com nada, não seria ninguém. (Mônica, 47 anos).

Chama a atenção, além da depreciação atribuída, a profunda ameaça à identidade contida na frase "sem ele eu [...] não seria ninguém", ou seja, aos olhos do marido (pelo menos na esfera do falado), para ela "ser alguém" implicava estar ao seu lado, depender dele e submeter-se às suas vontades. Quer dizer, sem ele, ela simplesmente "não seria". Por outro lado, a reação da esposa revelou a incorporação do discurso do parceiro ao assumir a postura por ele desejada, aquela de acordo com a construção tradicional de gênero, da "mulher para o lar":

[...] ele querendo que eu ficasse cada vez mais casadinha, mais maria [...] não percebi esse movimento, porque eu tava frágil.[...] eu fiquei maria, mariazona [...] aí eu fui ficando cada vez mais acuada e mais medrosa. (Mônica, 47 anos).

Esse recorte nos leva a pensar na concepção de um não sujeito, heterônomo e dependente do outro para existir como pessoa. Assim, a "maria" da interlocutora traduziria a condição feminina de viver para a casa, para o marido e para os filhos. Ao se analisar mais atentamente o conteúdo da fala de Mônica, depreende-se que a submissão e a dependência não eram posturas por ela assumidas inicialmente, mas que foram se configurando paulatinamente, à medida que, sentindose "acuada e medrosa", ela aceitava o papel requerido. É nesse sentido que consideramos o exercício da violência, em tais circunstâncias, como uma ameaça à identidade, uma vez que, dentro do jogo relacional com poderes circulando 
de forma hierárquica, aquele que detém maiores recursos tem a possibilidade

de influenciar negativamente a construção identitária do sujeito em situação desvantajosa através de armas simbólicas, como cremos serem as agressões psicológicas relatadas pela participante (PAZO; AGUIAR, 2012; MACHADO; MAGALHÃES, 1998).

Outra faceta da prática de violência no conflito conjugal como uma forma de ameaça à identidade subjetiva e que consideramos extremamente relevante ao presente estudo foi levantada por Lara ao dizer que, em todos os episódios de violência física, o seu rosto era sempre o principal alvo do marido: "o negócio dele era dar murro no rosto". Ao ser inquirida sobre o quê, em sua opinião, levaria o marido a ter "predileção" pela face, ela atribuiu um sentido muito particular às agressōes que sofreu:

[...] eu acho que, assim, o nosso rosto é nossa identidade, né? É nossa identidade. Eu acho que é pra me agredir a minha identidade, o meu eu. Se ele bater em nosso braço, nossa perna [...] o braço, a perna, as costas não seria a minha identidade, o meu eu, eu acho isso. (Lara, 44 anos)

Considerando que, na história narrada, não houve menção a alterações faciais permanentes decorrentes dos golpes, cremos que neste trecho ela se refere principalmente à subjetividade. A afirmação "nosso rosto é nossa identidade" alude à ideia de que a face humana representa muito mais que os traços fisionômicos ali localizados (LE BRETON, 2009; 2006; YU, 2001). Chama atenção a sintonia desta fala com um trecho do livro $A$ sociologia do corpo, que versa:

$\mathrm{O}$ rosto é, de todas as partes do corpo humano, aquela onde se condensam os valores mais elevados. Nele cristalizam-se os sentimentos de identidade, estabelece-se o reconhecimento do outro, fixam-se qualidades da sedução, identifica-se o sexo, etc. [...] Um machucado, mesmo que grave, no braço, na perna ou na barriga não enfeia, não modifica o sentimento de identidade. (LE BRETON, 2006, p. 70-71).

Ao cotejar os dois recortes, percebemos observações análogas. O primeiro, na esfera do experienciado, Lara estabelece o link entre o rosto concreto (aquele que é golpeado fisicamente) e o plano abstrato contido nas expressões "minha identidade" e "meu eu". O segundo, no âmbito teórico, o autor, ao se referir a um sítio corpóreo, confere-lhe atributos imateriais como "valores mais elevados" e "sentimentos de identidade". Ou seja, apesar de ser uma das partes do corpo, a face se distingue das demais ao alojar, simbolicamente, qualidades concedidas socialmente que podem ser significadas de acordo com o contexto vivenciado. 


\section{Considerações finais}

As experiências de vitimização relatadas pelas participantes do estudo evidenciaram o caráter invasivo da violência conjugal, especialmente a do tipo físico que, ao ultrapassar arbitrariamente as fronteiras do corpo da mulher, tende a deixar marcas, não só concretas, mas também simbólicas. Nesse sentido, o rosto feminino, ao se tornar o alvo preferencial do par afetivo agressor, convertese em um espaço no qual os sinais, temporários ou permanentes, ali plantados propendem a assumir significado de demarcação do território corporal como se fossem bandeiras sinalizadoras da violência cometida.

Portanto, estabelecer nexos entre o conteúdo analisado neste trabalho com dados epidemiológicos que apontam para a ocorrência de lesões buco-maxilofaciais em mulheres vitimizadas por parceiro íntimo em até $81 \%$ dos casos (LE et al., 2001), leva-nos a ponderar sobre a magnitude desse problema e de suas implicaçôes nos planos micro e macrossocial, gerando necessidades que requerem ações na perspectiva da integralidade da rede assistencial.

Focalizando a persistente predominância do modelo biomédico como referência de atenção aos que recorrem aos serviços de saúde em busca de atendimento, avaliamos este padrão, que privilegia, sobretudo, os aspectos físicos dos agravos, como insuficiente para dar respostas condizentes com a complexidade envolvida em casos de vitimização conjugal (SARTI, 2005). São vivências traumáticas que carregam, além dos danos ao corpo, profundas feridas emocionais que dificilmente serão superadas sem o acompanhamento articulado das várias esferas de atuação que tangenciam esse fenômeno. ${ }^{3}$

\section{Referências}

AZEVEDO, M.A. Mulheres espancadas: a violência denunciada. São Paulo: Cortez, 1985.

BAUER, M.W. Análise de conteúdo clássica: uma revisão. In: BAUER, M.W.; GASKELL,G. (Orgs.). Pesquisa qualitativa com texto, imagem e som: um manual prático. Petrópolis: Vozes, 2002, p. 189-217.

CARVALHO, T.B.O. et al. Six years of facial trauma care: epidemiological analysis of 355 cases. Braz J Otorhinolaryngol., v. 76, n. 5, p. 565-574, 2010.

DOMÍNGUEZ, A.C. Conceptos fundamentales de victimologia. Fundación Instituto de Victimologia. Madrid, 2010. Disponível em: <www.institutodevictimologia.com>. Acesso em: 10 dez 2012. 
FEIGUIN, D.; BORDINI, E.B.T. Reflexões sobre a violência contra a mulher. Revista da Fundação SEADE, v. 1, n. 2, 1987.

FEMENIAS, M.L.; ROSSI, P.S. Poder y violência sobre el cuerpo de las mujeres. Sociologias, v. 11, n. 21, p. 42-65, 2009.

GARCIA MORENO, C. et al. Prevalence of intimate partner violence: findings from the WHO multicountry study on women's health and domestic violence. Geneva, 2006.

GROSSI, M.P. Rimando amor e dor: reflexôes sobre a violência no vínculo afetivoconjugal. In: PEDRO, J.M.; GROSSI, M.P. Masculino, feminino, plural: gênero na interdisciplinaridade. Florianópolis: Mulheres, 1998, p. 293-313.

HALPERN, L.R. Orofacial injuries as markers for intimate partner violence. Oral maxillofacial Surg Clin, n. 22, p. 239-246, 2010.

HEISE, L.; GARCIA-MORENO, C. Violence by intimate partners. In: Krug, E.G. et al. World Report on Violence and Health. Geneva: WHO, 2002, p. 89-121.

LE BRETON, D. A sociologia do corpo. Petrópolis: Vozes, 2006.

. As paixôes ordinárias: antropologia das emoçōes. Petrópolis: Vozes, 2009.

LE, B.T. et al. Maxillofacial injuries associated with domestic violence. J Oral Maxillofac Surg, v. 59, n. 11, p. 1.277-1.283, 2001.

MACEDO, J.L.S. et al. Perfil epidemiológico do trauma de face dos pacientes atendidos no pronto socorro de um hospital público. Rev. Col.Bras. Cir., v. 35, n. 1, 2008.

MACHADO, L.Z.; MAGALHĀES, M.T.B. Violência conjugal: os espelhos e as marcas. Série Antropologia. Brasília, n. 240, p. 1-34, 1998. Disponível em: <http://www.dan.unb.br/ images/doc/Serie240empdf.pdf> Acesso em: 20 mar 2012.

PAZO, C.G.; AGUIAR, A.C. Sentidos da violência conjugal: análise do banco de dados de um serviço telefônico anônimo. Physis Revista de Saúde Coletiva, v. 22, n. 1, p. 253-273, 2012. SADDKI, N.; SUHAIMI, A.A.; DAUD, R. Maxillofacial injuries associated with intimate partner violence in women. BMC Public Health, v. 10, n. 268, 2010.

SAFFIOTI, H.I.B. Gênero, patriarcado, violência. São Paulo: Fundação Perseu Abramo, 2004.

SARDENBERG, C.M.B. A mulher frente à cultura da eterna juventude: reflexões teóricas e pessoais de uma feminista "cinquentona". In: FERREIRA, S.L.; NASCIMENTO, E.R. (Org.). Imagens da mulher na cultura contemporânea. Salvador: NEIM/UFBA, 2002, p. 5168 (Coleção Bahianas, n. 7).

SARTI, C.A. O atendimento de emergência a corpos feridos por atos violentos. Physis: Revista de Saúde Coletiva. Rio de Janeiro, v. 15, n. 1, p. 107-126, 2005.

SCHRAIBER, L.B. et al. Violência contra a mulher: estudo em uma unidade de atenção primária à saúde. Rev Saúde Pública, v.36, n.4, p. 470-7, 2002. 
SUÁREZ, M.; BANDEIRA, L. A politização da violência contra a mulher e o fortalecimento da cidadania. In: BRUSCHINI, C.; UNBERBHAUM, S.G. (Org.). Gênero, democracia e sociedade brasileira. São Paulo: Editora 34, 2002, p. 295-320.

YU, N. What does face mean to us? Pragmatics \& Cognition, v. 9, n. 1, p. 1-36, 2001.

ZANATTA, M.S. Nas teias da identidade: contribuições para a discussão do conceito de identidade na teoria sociológica. Perspectiva, Erechim, v. 35, n. 132, p. 41-54, 2011.

\section{Notas}

${ }^{1}$ O estudo foi aprovado pelo Comitê de Ética em Pesquisa do Instituto de Saúde Coletiva (CEP-ISC/ UFBA) sob parecer no 035-12/CEP-ISC, de junho de 2012, atendendo à Resolução no 196/96 do Conselho Nacional de Saúde.

${ }^{2}$ Os nomes utilizados para todas as entrevistadas são fictícios.

${ }^{3}$ S.M. Dourado trabalhou na concepção e execução da pesquisa; análise e interpretação dos dados; e na redação do artigo. C.V. Noronha orientou a dissertação que deu origem ao artigo; colaborou na análise e interpretação dos dados e na redação do artigo. 
The marked face: the multiple implications of female victimization in loving relationships

This paper analyses female narratives about violent marital relationships, specifically, cases in which facial damages have occurred to women assaulted by an intimate partner. The research aimed to apprehend the meanings of the violence to the victims and also to identify the implications of victimizing experience. The study was conducted by interviews with women attending public institutions such as women police station, health unit, psychosocial support service and educational facility. The analysis, under the sociology of the body view, highlighted the pervasiveness of violent actions that target the female face due emotional and physical marks that will reverberate, in short and long term, in the lives of victimized women. In the light of relational feminist perspective, issues pertaining to both partners in the production of violent interaction have emerged, mediated by social gender constructs. Reverberations of the violent acts over the sense of identity and depreciation of selfimage were emphasized as intense psychological suffering sources. The results also point to limits of biomedical model of care, still prevalent in health services, to deal with the complexity involved in marital female victimization and to the need of articulation among the various sectors that this phenomenon concerns.

> Key words: intimate partner violence; facial damages; victimization; subjectivity. 